\title{
Partial coupling and differential regulation of biologically and photochemically labile dissolved organic carbon across boreal aquatic networks
}

\author{
J.-F. Lapierre ${ }^{1, *}$ and P. A. del Giorgio ${ }^{1}$ \\ ${ }^{1}$ Groupe de Recherche Interuniversitaire en Limnologie et en Environnement Aquatique (GRIL), Département des Sciences \\ Biologiques, Université du Québec à Montréal, Case Postale 8888, succursale Centre-Ville, Montréal, QC, H3C 3P8, Canada \\ * current address: Department of Fisheries and Wildlife, Michigan State University 480 Wilson Rd, Resources Bldg, \\ East Lansing, MI, 48824, USA
}

Correspondence to: J.-F. Lapierre (jfrancoislapierre@gmail.com)

Received: 2 April 2014 - Published in Biogeosciences Discuss.: 8 May 2014

Revised: 2 August 2014 - Accepted: 17 September 2014 - Published: 31 October 2014

\begin{abstract}
Despite the rapidly increasing volume of research on the biological and photochemical degradation of DOC (dissolved organic carbon) in aquatic environments, little is known of the large-scale patterns in biologically and photochemically degradable DOC (BDOC and PDOC, respectively) in continental watersheds, and on the links that exist between these two key properties that greatly influence the flow of carbon from continents to oceans. Here we explored the patterns in the concentrations and proportions of BDOC and PDOC across hundreds of boreal lakes, rivers and wetlands spanning a large range of system trophic status and terrestrial influence, and compared the drivers of these two reactive pools of DOC at the landscape level. Using standardized incubations of natural waters, we found that the concentrations of BDOC and PDOC covaried across all systems studied but were nevertheless related to different pools of dissolved organic matter (DOM; identified by fluorescence analyses) in ambient waters. Concentrations of nutrients and protein-like fluorescent DOM (FDOM) explained nearly half of the variation in BDOC, whereas PDOC was exclusively predicted by DOM optical properties, consistent with the photochemical degradability of specific FDOM pools that we experimentally determined. The concentrations of colored DOM (CDOM), which we use here as a proxy of terrestrial influence, almost entirely accounted for the observed relationship between FDOM and the concentrations of both BDOC and PDOC. The concentrations of CDOM and of the putative biolabile fluorescence component shifted from com-
\end{abstract}

plete decoupling in clear-water environments to strong coupling in darker streams and wetlands. This suggests a baseline autochthonous BDOC pool fueled by internal production that is gradually overwhelmed by land-derived BDOC as terrestrial influence increases across landscape gradients. The importance of land as a major source of both biologically and photochemically degradable DOC for continental watersheds resulted in a partial coupling of those carbon pools in natural freshwaters, despite fundamental contrasts in terms of their composition and regulation.

\section{Introduction}

The movement of terrestrial dissolved organic carbon (DOC) from the land-water interface to the oceans is mediated by its transit through complex and highly heterogeneous continental freshwater networks, where DOC from different sources and origins is simultaneously produced and removed via biotic and abiotic processes (Massicotte and Frenette, 2011; Cole et al., 2007; Battin et al., 2008). The overall role that DOC plays on aquatic ecosystems is well recognized (Findlay and Sinsabaugh, 2002), but there is still debate regarding the direct role of terrestrially derived organic carbon as a substrate for ecological and biogeochemical processes in freshwater ecosystems. More specifically, it is generally accepted that terrestrial DOC may support food webs at various trophic levels (Berggren et al., 2010b; Karlsson et al., 
2003; Jansson et al., 2007), as well as fuel $\mathrm{CO}_{2}$ evasion from these systems (Algesten et al., 2004; Lapierre et al., 2013; Berggren et al., 2012), but the relative importance for those processes compared to that of autochthonous sources of organic C (Brett et al., 2009; Wenzel et al., 2012), or terrestrially derived $\mathrm{CO}_{2}$ (Wallin et al., 2013; Butman and Raymond, 2011), respectively, is still questioned. This questioning largely emerges from unresolved issues concerning terrestrial organic carbon degradability in aquatic ecosystems, which then determines the ability of this carbon to enter aquatic food webs and biogeochemical cycles.

Microbial and photochemical degradation are the two main pathways by which terrestrial DOC may influence aquatic metabolism (del Giorgio et al., 1999; Obernosterer and Benner, 2004; Bertilsson and Tranvik, 1998) and gas dynamics (Molot and Dillon, 1997; Jonsson et al., 2001; Lapierre et al., 2013), and both processes operate simultaneously in ambient waters. Their magnitude and relative contribution in natural systems depend on environmental factors, such as light availability, water residence time and dissolved ions (Soumis et al., 2007), as well as on factors that are intrinsic to DOC (Guillemette and del Giorgio, 2011; Fasching et al., 2014). Microbial degradation is thought to preferentially target freshly produced, low-molecular weight molecules with low aromaticity (Amon and Benner, 1996; Wickland et al., 2007), whereas photochemical degradation mainly acts on colored, photoreactive molecules generally associated with high molecular weight and aromaticity (Benner and Kaiser, 2011; Bertilsson and Tranvik, 1998; Stubbins et al., 2010). These broad chemical properties have thus been associated with distinct pools of DOC with distinct sources (i.e., the process that imported DOC in the environment; e.g., leaching, exudation) and origins (i.e., the environments where these processes take place; e.g., terrestrial, riverine, marine).

Transposing the geochemical evidence described above to natural landscapes would suggest a shift in the relative importance of these DOC degradation pathways, from a dominance of biological degradation in systems dominated by autochthonous carbon sources, to a dominance of photochemical degradation in environments with high terrestrial influence. This scenario, which is based on the simplistic assumption that biological degradability is mostly linked to autochthonous DOC and that photochemical degradability is mostly associated with terrestrially derived DOC, would lead to a compensatory dynamic wherein the overall (biological + photochemical) degradability of DOC would be to some extent buffered across different environments and along a gradient of terrestrial influence.

Although the above assumption may hold for specific aquatic environments, it is unlikely that it applies at the landscape level, in part because there is increasing evidence that land exports to continental waters not only photochemically degradable DOC (Molot and Dillon, 1997; Jonsson et al., 2001; Weyhenmeyer et al., 2012), but also significant amounts of biologically degradable DOC (Berggren et al., 2010a; Fellman et al., 2008; Guillemette et al., 2013). For example, significant concentrations of protein-like DOC and small organic acids, typically attributed to autochthonous and biolabile material, have been measured in soils and headwater streams (Berggren et al., 2010a; Fellman et al., 2009), and carbon pools that are considered recalcitrant from a geochemical perspective (based on their molecular properties and degree of prior processing) may actually be biologically degradable under the right environmental conditions, in soils (Schmidt et al., 2011) or in the water (Marín-Spiotta et al., 2014; Ward et al., 2013; Fasching et al., 2014). This implies that there may be a faster turnover of terrestrially derived DOC in inland waters than what was previously thought, yet there is a large volume of literature documenting the recalcitrance of this carbon in marine or riverine environments with high residence time (see synthesis by Marín-Spiotta et al., 2014). This would suggest that the degradability of terrestrial DOC may be very different in contrasting aquatic environments and, in particular, that it becomes increasingly stable with time as it circulates through continental watersheds, where the labile portions of the DOC pool imported from upstream are gradually processed and removed from the bulk.

It thus appears that land delivers to inland waters a DOC pool that, depending on the local environmental context, may be both biologically and photochemically degradable. If indeed biologically and photochemically degradable DOC share, to a certain degree, similar sources and origins, one could expect both functional pools of DOC to covary across aquatic environments. This would lead to an additive rather than compensatory dynamic, wherein the overall degradability of DOC would increase as a function of increasing terrestrial export, with major implications for the aquatic carbon cycle. Previous evidence has shown that both BDOC and PDOC (biologically and photochemically degradable DOC) tend to increase in boreal freshwaters with increasing terrestrial influence (Lapierre et al., 2013), but the respective drivers of those pools and the degree to which they are coupled across a large diversity of freshwater environments remain unclear; few if any studies have simultaneously assessed the magnitude and regulation of biological and photochemical degradability across gradients representative of aquatic ecosystems at a landscape level. Here we explore the patterns in the concentrations and proportions of biologically and photochemically degradable DOC across boreal lakes, rivers and wetlands, and the degree to which those distinct pools of DOC covary in natural waters. We targeted this diversity of aquatic ecosystems because they represent the existing gradient in terms of connectivity with land and therefore in the extent of terrestrial influence on aquatic DOC dynamics. We then use a combination of optical and chemical properties in order to explore how intrinsic DOC composition and extrinsic environmental properties respectively drive the concentrations of BDOC and PDOC in boreal natural waters. Finally, we explore how a continuous gradient 


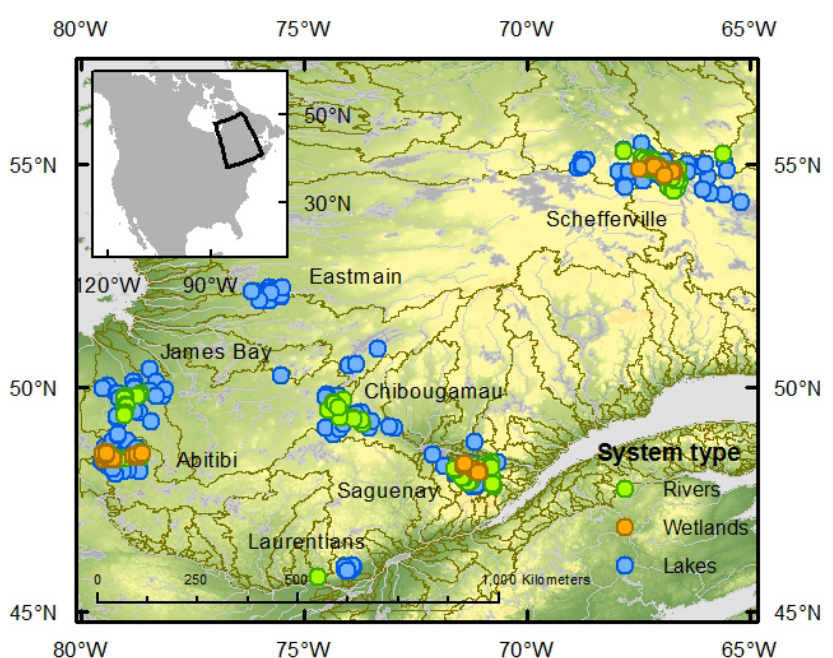

Figure 1. Distribution of the sampling sites across seven boreal regions (James Bay, Abitibi, Laurentians, Saguenay, Chibougamau, Schefferville) of Quebec, Canada. Grey lines and areas represent large rivers and lakes; green lines delimit the main watersheds in Quebec.

of terrestrial influence (using CDOM - colored dissolved organic matter - as a proxy; see Lapierre et al., 2013) may underlie the patterns in the concentrations of degradable DOC across diverse and complex freshwater networks.

\section{Methods}

\subsection{Study regions and sampling}

Over the summer period from 2009 to 2013 we sampled a wide range of lakes (236), streams (204), rivers and wetlands (83; mostly beaver ponds). Those systems span over a very large geographic range (Fig. 1), which translates into very diverse climate, landscape and limnological properties. In particular, mean annual temperature and precipitation ranged from -5.7 to $4.8^{\circ} \mathrm{C}$ and from 334 to $1289 \mathrm{~mm}$, respectively, and catchment vegetation ranged from mixed conifer and deciduous in the south to black spruce moss forest in the north; tundra-type vegetation covered the northernmost, highest altitude sites. Aquatic environmental properties spanned over most of the freshwater gradients reported in the literature, with DOC, CDOM (a440 nm, Naperian units), TN (total nitrogen), TP (total phosphorus) and Chl $a$ concentrations ranging from $0.4-123.9 \mathrm{mg} \mathrm{L}^{-1}, 0.05-30.0 \mathrm{~m}^{-1}, 0.03-$ $1.90 \mathrm{mg} \mathrm{L}^{-1}, 2.24-248.2 \mu \mathrm{g} \mathrm{L}^{-1}$ and $0.1-100.7 \mu \mathrm{g} \mathrm{L}-1$, respectively, across the sampling sites (Lapierre et al., 2013). Hydrology and morphometry were also very different across the systems studied, with rivers ranging from Strahler order 1 to 6 , and lakes and wetlands ranging from 0.01 to $2300 \mathrm{~km}^{2}$ (Lapierre et al., 2013), as well as mean depth and discharge ranging over several orders of magnitude (Lapierre and del
Giorgio, 2012; Campeau et al., 2014). The different sites were seldom part of the same catchment except for the largest lakes and rivers that drained vast territories.

Water was sampled at $0.5 \mathrm{~m}$ from the surface, at the deepest measured location of the lakes. Water was also sampled near the shore of streams, rivers and wetlands and, in all cases, it was immediately filtered $(0.45 \mu \mathrm{m})$ and stored in acid-washed glass vials for DOC, optical analyses and inorganic N. Samples for total nitrogen TN and TP were also stored in acid-washed glass vials but were not filtered. All samples were immediately stored in cold and dark conditions. Analyses were typically performed within 1 month; optical measurements and inorganic $\mathrm{N}$ were typically performed within 2 weeks.

\subsection{Biological and chemical analyses}

DOC concentration was measured with an OI 1010 TIC-TOC (TX, USA) analyzer following sodium persulfate digestion. We analyzed TP spectrophotometrically after persulfate digestion and TN was analyzed as nitrate following alkaline persulfate digestion and measured with an Alpkem Flow Solution IV autoanalyzer; ambient nitrites and nitrates were measured individually prior to persulfate digestion (APHA, 1998). Ammonium was measured by fluorescence following Holmes et al. (1999). Chl $a$ samples were analyzed spectrophotometrically after filtration with Whatman $(\mathrm{GF} / \mathrm{F})$ filters and hot ethanol $(90 \%)$ extraction (Marker and Nusch, 1980). Filters were sonicated prior to extraction. Each of those variables has been collected in duplicates in the field; we present the mean here.

\subsubsection{Optical analyses}

The absorbance of CDOM was measured on nanopurecorrected samples of filtered ambient water from 230 to $700 \mathrm{~nm}$, using a UV (ultraviolet)-visible Ultrospec 2100 spectrometer (Biochrom, Cambridge, UK) and a $2 \mathrm{~cm}$ quartz cuvette. We report CDOM as the absorption coefficient at $440 \mathrm{~nm}\left(\mathrm{~m}^{-1}\right.$, Naperian units), calculated by dividing the optical absorbance at $440 \mathrm{~nm}$ by the path length in meters and multiplying by 2.303 (Cuthbert and del Giorgio, 1992). We also calculated proxies of DOC aromaticity and molecular weight by estimating the DOC specific absorbance at $254 \mathrm{~nm}\left(\mathrm{SUVA}_{254}\right)$ and the ratio of absorbance at 250 $365 \mathrm{~nm}$ (Spencer et al., 2009a), respectively. The former was calculated by dividing absorption coefficients at $254 \mathrm{~nm}$ by DOC concentration and the latter was directly obtained from the ratio of absorption coefficients at these specified wavelengths.

Fluorescence intensity was measured with a Shimadzu RF5301 PC (Shimadzu, Kyoto, Japan), across excitation wavelengths of $275-450 \mathrm{~nm}$ ( $5 \mathrm{~nm}$ increments) and emission wavelengths of $280-600 \mathrm{~nm}$ ( $2 \mathrm{~nm}$ increments) in order to build excitation-emission matrices (EEMs). A parallel factor 


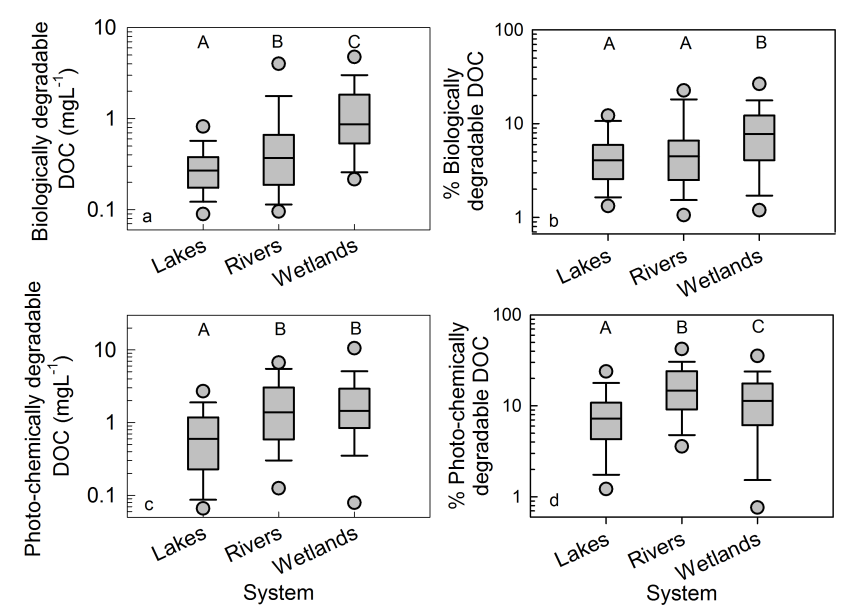

Figure 2. Amounts and proportions of biologically and photochemically degradable DOC across the three main types of systems studied. Lines represent the 25, 50 and 75 percentiles, points, 5 and 95 percentiles. Different letters denote statistically different $(p<0.01)$ means across groups, based on ANOVA (analysis of variance) and Tukey-Kramer post hoc analyses. BDOC (percent and absolute): $n=201$ for lakes, $n=71$ for rivers, $n=53$ for wetlands. PDOC (percent and absolute): $n=193$ for lakes, $n=136$ for rivers, $n=67$ for wetlands.

(PARAFAC) model (Stedmon et al., 2003) was developed to identify and quantify groups of DOM that shared similar optical properties and distribution across the sampled sites. Fluorescence data were corrected for inner-filter effect and standardized to Raman units using the FDOMcorr 1.6 toolbox (Murphy et al., 2010) in MATLAB (MathWorks, Natick, MA, USA). The model was based on 1349 samples from ambient waters and from photochemical degradation experiments, and was performed on corrected data using the DOMfluor 1.7 toolbox (Stedmon and Bro, 2008); only part of the data are reported here. The initial data set comprised 1577 samples; samples for which absorbance within the $1 \mathrm{~cm} \mathrm{cu}-$ vette was higher than 0.6 at $254 \mathrm{~nm}$ were excluded due to potential for ineffective inner-filter effect correction (Miller et al., 2010), which could bias the final model. We express the "concentrations" of fluorescence components as the maximum fluorescence intensity at the peak. These represent relative concentrations that may be used to explore the crosssample patterns for a given component, but this does not necessarily mean that one unit of a given component represents an equal amount of DOM compared to one unit of any other component.

\subsection{Biological and photochemical DOC degradation}

We carried out standardized biological and photochemical degradation experiments in order to derive a concentration of degradable DOC that did not depend on varying incubation conditions and would thus be fully comparable across ecosystems and in time (Lapierre et al., 2013). The experi-
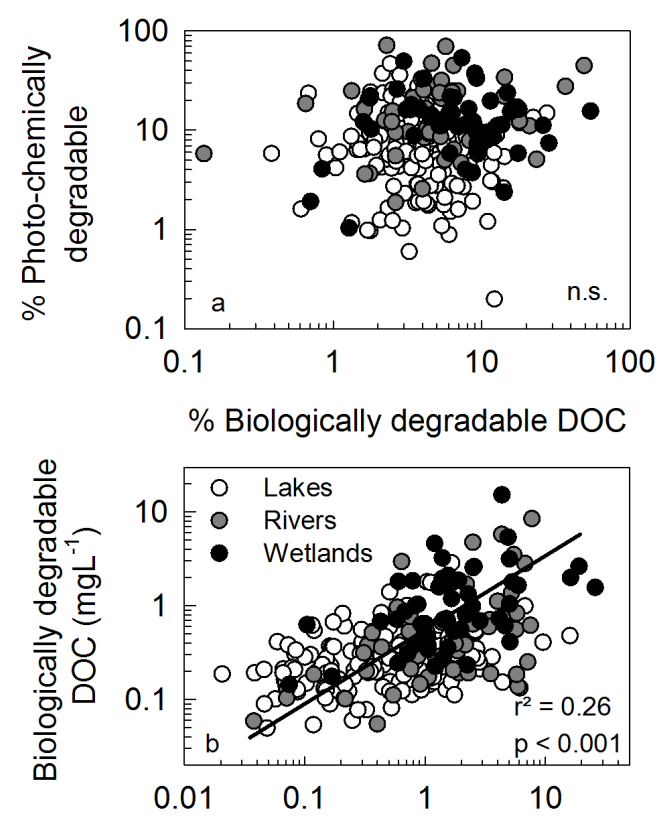

Photo-chemically degradable DOC $\left(\mathrm{mgL}^{-1}\right)$

Figure 3. Relationship between the proportions (a) and amounts (b) of biologically and photochemically degradable DOC across boreal lakes, rivers and wetlands. (a) $n=262$, not significant. (b) Lakes: $\log (\mathrm{BDOC})=0.16 \log (\mathrm{PDOC})-1.67, \quad p=0.0003, r^{2}=0.11$, $n=161$; rivers: $\log (\mathrm{BDOC})=0.88 \log (\mathrm{PDOC})-1.59, p<0.0001$, $r^{2}=0.33, \quad n=58 ; \quad$ wetlands: $\log (\mathrm{BDOC})=0.78 \log (\mathrm{PDOC})$ - 1.34, $p<0.0001, \quad r^{2}=0.23, \quad n=50$; overall relationship: $\log ($ BDOC $)=0.71 \log ($ PDOC $)-1.48, p<0.001, n=268$.

ments were started on the same day that the samples were collected. Biological degradation experiments were carried out in water that was filtered through $2.8 \mu \mathrm{m}$ nominal pore size GF/D filters (Whatman) in order to maintain the in situ bacterial community and thus to avoid re-inoculation. Water samples were incubated in the dark at a fixed incubation time (14 days) and temperature $\left(20^{\circ} \mathrm{C}\right)$. The results presented in Figs. 2 and 3 correspond to the concentrations in BDOC, expressed as the absolute amount of DOC removed over a period of 14 days, calculated as the difference in concentration before and after degradation. The percentage of degradable DOC was calculated as the fraction represented by the difference between DOC concentration at the start of the experiment and BDOC, multiplied by 100 .

A subset of the filtered $(2.8 \mu \mathrm{m})$ water was used for photochemical degradation experiments, which were carried out in a solar simulator (Qsun XE1-BC, Qlab, FL, USA) under a standard light dose $\left(0.68 \mathrm{~W} \mathrm{~m}^{-2}\right.$ at $340 \mathrm{~nm}$, spectrum representative of natural sunlight) in $24 \mathrm{~mm}$ diameter glass tubes disposed horizontally. Given the strong light dose and the small cross section of the tubes, there was a negligible effect of the CDOM concentrations on the effective light dose inside the tubes, even for the most colored samples 
(see Appendix A for details). The amount of light energy available in the vial for wavelengths comprised between 300 and $450 \mathrm{~nm}$, responsible for most photochemical processing of DOC (Vähätalo et al., 2000), averaged $130.8 \mathrm{~W} \mathrm{~m}^{-2}$ and did not vary substantially across samples due to self-shading (standard deviation $=9.2 \mathrm{~W} \mathrm{~m}^{-2} ; 10$ th and 90th percentiles $=118.4$ and $140.4 \mathrm{~W} \mathrm{~m}^{-2}$, respectively) compared to the range of variation measured in the concentrations of PDOC, which spanned several orders of magnitude. Consequently, standardizing the concentrations in PDOC for the corrected light dose in the corresponding tubes could in no way alter the patterns and conclusions of the current study (see Appendix Fig. A2). We therefore report the uncorrected values (in $\mathrm{mg} \mathrm{CL}^{-1}$ of photochemically degradable DOC). We assume that most bacteria could not survive the very strong UV dose and thus significantly contribute to the DOC loss in irradiation experiments; even if that were not the case, the DOC loss rates (expressed per day) were always at least 1 order of magnitude higher in photochemical degradation experiments compared to biological degradation experiments conducted in the dark (Lapierre et al., 2013).

Photoexposure time $(24 \mathrm{~h})$ and temperature $\left(24^{\circ} \mathrm{C}\right)$ were the same for all experiments (Lapierre et al., 2013). The data presented in Figs. 2 and 3 correspond to the amount of DOC removed in 1 day under those conditions; considering diel light cycles and the natural light intensity at the studied latitudes, this would roughly correspond to 6 days of natural light exposure in the sampled regions. Irradiated samples were stored in $40 \mathrm{~mL}$ glass tubes and directly analyzed for DOC concentration. We also measured DOM optical properties before and after irradiation for a subset $(n=187)$ of the samples. The fluorescence data were included in the PARAFAC model.

\subsection{Statistical analyses}

Analyses of variance, simple and multiple linear regressions and principal component analyses (PCAs) were performed on log-transformed data in JMP 7.0.1 software. Data were centered and standardized before performing the PCA. The best multiple linear regression (MLR) models were identified using forward step-wise selection based on change in the Akaike information criterion (AIC). Moving window regressions (MWRs) of fluorescence component C6 against CDOM concentrations were performed successively on subsets of 250 samples (about half of the sample size) sorted by increasing CDOM.

\section{Results}

\subsection{Patterns in the amounts and proportions of degradable DOC}

The amounts of DOC removed in these standardized incubations ranged from 0.05 to $15.2 \mathrm{mg} \mathrm{L}^{-1}$ and from almost
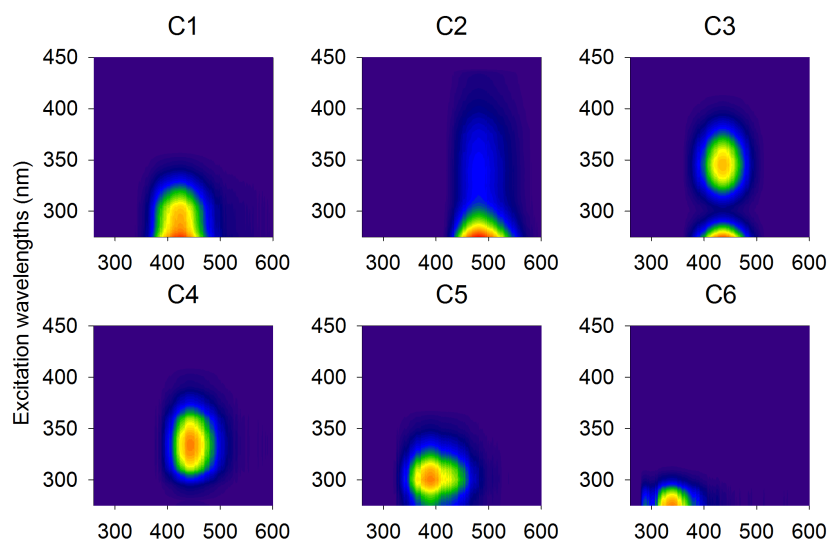

Emission wavelengths ( $\mathrm{nm})$

Figure 4. Fluorescence signatures of the components identified by the PARAFAC model. Fluorescence peaks are observed at the following wavelengths ( $\mathrm{nm})$, for excitation and emission, respectively (secondary peak in parentheses): C1: 275, 424; C2: 275(340), 484; C3: 275(345), 436; C4: 334, 446; C5: 300, 388; C6: 275, 334.

0 to $26.0 \mathrm{mg} \mathrm{L}^{-1}$, for biological and photochemical degradation, respectively (Fig. 2). This represented 0.13-54.3\%, and $0.04-72.6 \%$ of the ambient DOC pool where those samples were collected, respectively (Fig. 2). These numbers represent potential degradation under standardized conditions and depending on environmental conditions may not be expressed in situ; they should not be considered as representative of ambient rates. They do, however, allow us to isolate DOC degradability while minimizing the influence of sitespecific conditions, such as temperature or irradiation, and thus to explore the patterns and drivers of this degradability over a large range of DOC properties.

The amounts and proportions of degradable DOC were typically lower in lakes than in rivers and wetlands (Fig. 2). Both the amounts and proportions of BDOC were highest in wetlands, whereas rivers contained the highest proportions of PDOC, but similar amounts of PDOC compared to wetlands (Fig. 2). There was no relationship at all between the percentage of BDOC and PDOC across the ensemble of almost 300 lakes, rivers and wetlands for which those measurements were available (Fig. 3a). There was, however, a significant positive relationship between the absolute amounts of BDOC and PDOC in lakes, rivers and wetlands separately. There was thus a significant coupling between both pools of DOC when all the systems were considered together, and this coupling was typically stronger in rivers and wetlands than in lakes (Fig. 3b). There was a very large scatter around the regression, however, and concentrations of PDOC ranged by more than 1 order of magnitude for any given amount of $\mathrm{BDOC}$, and vice versa. 


\subsection{The PARAFAC model}

The PARAFAC model identified six fluorescence components (Fig. 4), corresponding to humic-, fulvic- and proteinlike materials that are widely reported in freshwaters. In particular, quantitative comparison of our components to published components (using OpenFluor database; Murphy et al., 2014) revealed that components $\mathrm{C} 1$ and $\mathrm{C} 2$ reported here matched very well previously reported humic-like, terrestrially derived material identified in a variety of aquatic environments (Stedmon et al., 2003; Shutova et al., 2014). Components C5 and C6 matched widely reported components (Cory and McKnight, 2005; Fellman et al., 2008; Kothawala et al., 2013b, among others), which have been associated with microbially derived humic-like and freshly produced protein-like material, respectively. The whole spectra of components $\mathrm{C} 3$ and $\mathrm{C} 4$ did not show a strong match with any fluorescence component published in the OpenFluor database, but had fluorescence peaks comparable to other published humic- and fulvic-like material (Guillemette and del Giorgio 2012, Lu et al 2013); these components had excitation spectra ranging in the UV-B and UV-A regions (Fig. 4), indicating that they strongly absorb light at those wavelengths.

Although the model was not run with samples with the highest absorbance, as described in the Methods section, it was subsequently used to estimate the concentration of fluorescence components in highly colored samples for which the inner-effect correction may not be optimal. Hence, for the 43 samples with absorbance ranging from 0.6 to up to 1.2 at $254 \mathrm{~nm}\left(\mathrm{~cm}^{-1}\right)$, the concentration of tryptophan-like component C6 may have been slightly underestimated whereas the concentration of the remaining fulvic- and humic-like components may have been overestimated by up to $20 \%$ (Miller et al., 2010). Recent findings, however, suggest that the correction that we have performed adequately corrects for innerfilter effect for absorbance up to $1.5 \mathrm{~cm}^{-1}$, such that the bias, if any, would actually be much smaller (Kothawala et al., 2013a) Similar to the range of variation in PDOC, the concentrations in the different fluorescence components varied by several orders of magnitude across the sampled sites, and thus the small bias that may be present in these 43 highly colored samples is unlikely to influence the patterns reported here.

\subsection{Linking patterns in degradable DOC to DOM composition and nutrients}

There were significant differences in the amounts and proportions of degradable DOC across different types of systems (Fig. 2), and a principal component analysis (PCA) further shows that lakes, rivers and wetlands tend to group not only in terms of concentrations of total and degradable DOC, but also in terms of DOM composition and nutrient concentrations (Fig. 5). The concentrations of DOC, CDOM, the indi-

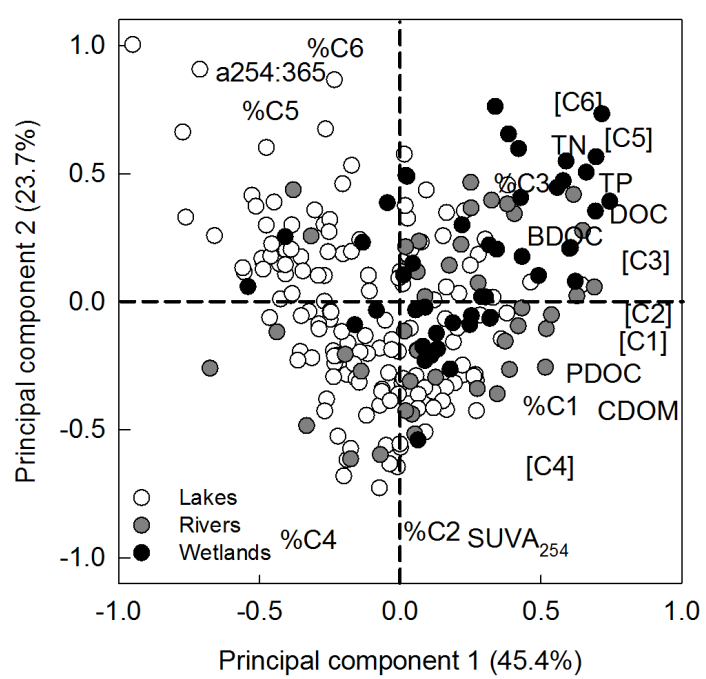

Figure 5. Principal component analysis of concentrations of degradable DOM, DOM optical properties and nutrients across boreal lakes, rivers and wetlands. Abbreviations are defined in the text. Fluorescence components in square brackets correspond to the absolute concentration of the specified component.

vidual fluorescence components identified by the PARAFAC model, and nutrients all tended to covary along a "concentration" axis (component 1 of the PCA plot), which explained $45.4 \%$ of the total variability in the measured variables (Fig. 5). Fluorescence components $\mathrm{C} 1, \mathrm{C} 2$ and $\mathrm{C} 3$, as well as CDOM had the highest loadings on axis 1, and rivers and wetlands tended to have the highest scores on this axis. The absolute amounts of BDOC and PDOC were also positively associated with this axis, implying that systems with higher amounts of DOM and nutrients tended to have overall more degradable DOC.

The links between DOC degradability and composition are captured by the second axis of the PCA, which explained $23.7 \%$ of the variability. Concentrations of nutrients, as well as concentrations and proportions of protein-like C5 and C6, are all situated in the top half of the PCA, along with the a250:365 absorbance ratio (proxy of low molecular weight) and BDOC, whereas the amounts and proportions of humicor fulvic-like C1, C2 and C4, as well as $\mathrm{SUVA}_{254}$ and PDOC, clustered in the lower half of the PCA (Fig. 5); there was no clear system-specific distinction along this "composition" axis. These results suggest that whereas the absolute amounts of biological and photochemical degradability are both associated with the total amount of DOC, these two aspects of degradability are clearly linked to distinct pools within the bulk DOC. 
Table 1. Multiple linear regression models predicting the concentrations of photochemically and biologically degradable DOC across boreal lakes, rivers and wetlands. Abbreviations are defined in the text. Fluorescence components in square brackets correspond to the absolute concentration of the specified component. The sign in parentheses denotes the sign of the coefficient in the MLR model.

\begin{tabular}{lcllll}
\hline Response variable & Model & Predictors & $n$ & Adjusted $r^{2}$ & AIC \\
\hline BDOC & $\mathrm{a}$ & $(+)[\mathrm{C} 6]$ & 323 & 0.35 & -675 \\
& $\mathrm{~b}$ & $(+) \mathrm{TN}$ & 319 & 0.40 & -683 \\
& $\mathrm{c}$ & $(+) \mathrm{TN},(+) \mathrm{CDOM}$ & 317 & 0.45 & -696 \\
& $\mathrm{~d}$ & $(+) \mathrm{TN},(+)[\mathrm{C} 6]$ & 317 & 0.45 & -693 \\
& $\mathrm{e}$ & $(+) \mathrm{TN},(+)[\mathrm{C} 6],(+) \mathrm{TP}$ & 316 & 0.46 & -699 \\
\hline PDOC & $\mathrm{f}$ & $(+)[\mathrm{C} 3],(-) \% \mathrm{C} 5,(-) \% \mathrm{C} 6$ & 392 & 0.67 & -818 \\
& $\mathrm{~g}$ & $(+) \mathrm{CDOM},(+) \% \mathrm{C} 3,(-) \% \mathrm{C} 6$ & 392 & 0.73 & -887 \\
\hline Residuals of Pd-DOC vs. Bd-DOC & $\mathrm{h}$ & $(+) \% \mathrm{C} 3,(+) \mathrm{CDOM},(-) \% \mathrm{C} 6,(-) \mathrm{TP}$ & 264 & 0.27 & -406 \\
\hline
\end{tabular}

\subsection{The drivers of the concentrations of biologically and photochemically degradable DOC}

The differential regulation of BDOC and PDOC is more clearly expressed by their direct relationships with nutrients and the various DOM components (Table 1); $\mathrm{pH}$ and the concentration of $\mathrm{Chl} a$ were not significant predictors when the variables presented in Table 1 were included. Likewise, the inclusion of a categorical variable for system type (lake, river, wetland), or for the sampling region (see Fig. 1) did not improve the fit in multiple regression models predicting either component of degradability. There were thus no systematic ecosystem- or region-specific differences in the relationship between BDOC and its predictors, suggesting that the amount of biologically degradable DOC in the studied systems is mainly a function of DOM composition and nutrients regardless of the type of aquatic environment and the region where they lie.

BDOC was strongly related to both DOM and nutrient concentrations (Fig. 5, Table 1), and TN was the strongest single predictor (Table 1). Among the fluorescence components, the concentration of protein-like component C6 was the strongest predictor of BDOC (Table 1, model a); no other component had a significant effect on BDOC once C6 was included. In contrast to BDOC, DOM optical properties played a greater role as predictors of PDOC. The best MLR models for PDOC included a positive relationship with both the abundance and the relative proportions of component $\mathrm{C} 3$, and negative relationships with the proportions of components C5 and C6 (Table 1). The EEMs analysis allowed identifying specific pools of DOM that were particularly linked to ambient DOC biological or photochemical degradability, but the concentration aspect was mostly captured by CDOM (measured as absorbance at $440 \mathrm{~nm}$; see Methods) alone in both cases (Table 1, models c, g). In particular, when concentrations of CDOM were included in MLR, no other variable associated with concentration of DOM was significant in predicting PDOC, but qualitative aspects of DOM, such as the percent contribution of C3 and C6 (the latter negatively related), still significantly improved the model.

\subsection{Factors influencing the relationship between the concentrations of biologically and photochemically degradable DOC}

The above patterns in nutrients and DOM concentration and composition were reflected in the residuals of the relationship between BDOC and PDOC. Sites with higher concentrations of CDOM and proportions of the very photochemically degradable fluorescence component $\mathrm{C} 3$ (see below) tended to contain more PDOC per unit of BDOC (Table 1, model h). Conversely, sites with higher proportions of protein-like component $\mathrm{C} 6$ and higher nutrient concentrations tended to have a DOC pool that was more biologically degradable per unit of PDOC.

\subsection{Susceptibility of DOM components to photochemical degradation}

We further explored the photochemical degradability of specific pools of DOM in a subset of the irradiation experiments. Component $\mathrm{C} 3$, which emerged as one of the main drivers of PDOC, was extremely photosensitive and was often completely removed after $12-24 \mathrm{~h}$ of irradiation. In contrast, components $\mathrm{C} 5$ and $\mathrm{C} 6$, the latter being a major driver of BDOC (Table 1), appeared to be largely un-reactive to irradiation, whereas the concentration of component $\mathrm{C} 4$ systematically increased following irradiation, suggesting the photochemically mediated production of this component. Components 1 and 2 showed an intermediate photochemical degradability, with an average loss of 24 and $57 \%$, respectively, of their initial fluorescence during incubations (Fig. 6). It is interesting to note that these patterns of selective photochemical degradation of specific DOC components were very consistent among ecosystem types and regions (see error bars in Fig. 6). 


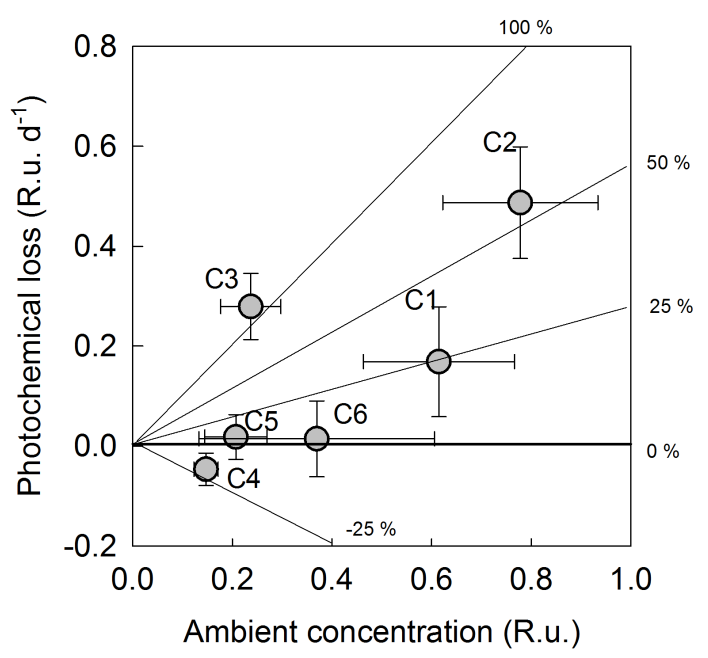

Figure 6. Average loss of specific fluorescence components based on the difference in concentration before and after irradiation for samples originating from boreal lakes, rivers and wetlands. Rates have been reported on a per day basis based on the average of the FDOM (fluorescent DOM) loss measured after 12 and $24 \mathrm{~h}$; this allowed us to better quantify the photochemical susceptibility of C3 which was commonly completely degraded after $24 \mathrm{~h}$, hence the average per day loss of over $100 \% . n=121$.

\subsection{Patterns of biologically and photochemically degradable DOC across gradients of terrestrial influence}

Despite the fact that different pools of DOM were linked to the concentrations of PDOC vs. BDOC (Table 1), CDOM itself accounted for as much variability in both PDOC and BDOC as any combination of fluorescence components, in terms of concentration. Coherent with the PCA (Fig. 5), this suggests that environments with high terrestrial influence also have higher concentrations and proportions of specific DOC pools associated with both PDOC and BDOC. Figure 5 shows the very strong relationships that exist between $\mathrm{CDOM}$ and the photosensitive fluorescence components $\mathrm{C} 2$ and $\mathrm{C} 3$. The relationship between CDOM and component C6, which was linked to BDOC, was less obvious in the PCA (Fig. 5). In this regard, there was an overall weak positive relationship between CDOM and C6 (Fig. 7a). Interestingly, the shape of this relationship varied greatly over a gradient of terrestrial influence (using CDOM as a proxy; see Lapierre et al., 2013). An analysis of discrete portions of this gradient using moving window regression (MWR) showed that the relationship between $\mathrm{C} 6$ and $\mathrm{CDOM}$ was not significant in low-CDOM environments (Fig. 7b), but became significant at CDOM (a440) concentrations of approximately $3 \mathrm{~m}^{-1}$. Beyond this point, both the $r^{2}$ and the slope of the relationship consistently increased with CDOM concentration until the slope stabilized when the lowest CDOM in the MWR was around $4 \mathrm{~m}^{-1}$. There was thus a strong link between CDOM and C6 in systems with elevated CDOM concentrations ranging from 4 to $30 \mathrm{~m}^{-1}$. These results indicate that the amount of biolabile DOC, as reflected by the C6 component of DOM, is completely uncoupled to CDOM at low levels of water color, but that the two become strongly coupled in systems with stronger terrestrial influence.

\section{Discussion}

\subsection{Origin, age, freshness and degradability of DOC}

The core result that we report here is that the concentrations of biologically and photochemically degradable DOC are uncoupled within any particular site, but that they nevertheless tend to positively covary across large geographical and environmental gradients and, in particular, along a gradient of terrestrial influence (Fig. 3b). These two functional groups of DOC are associated with compositionally distinct pools that are subject to differential regulation across the landscape, and their coupling is only apparent when both aspects of DOC degradability are assessed simultaneously over very broad gradients of terrestrial influence and across a wide range of aquatic ecosystems, as we have done in this study. This pattern likely reflects the expression of the different intrinsic DOC properties as well as environmental conditions (Guillemette and del Giorgio, 2011; Marín-Spiotta et al., 2014) that are encountered across the very diverse natural freshwater environments studied here.

The prevailing view on aquatic DOC biological degradability has been based on the notion that material from autochthonous origin is typically fresh and highly degradable whereas material from terrestrial origin tends to be old and highly altered, and thus does not contribute much to microbial processes (Hedges et al., 1988; Dittmar and Kattner, 2003; Amon and Benner, 1996). Origin and age, however, have different implications and different links to the notion of "freshness" (defined as the time relative to when DOM left its site of production, e.g., soil, aquatic organisms, and was imported into the aquatic environment) in different types of systems. For instance, in the open ocean, freshly produced is synonymous with autochthonous and young, whereas terrestrially derived implies leftovers of a pool that entered the aquatic network months, years or even centuries before (Anderson and Williams, 1999), and is therefore both old and diagenetically altered. The terrestrially derived DOC pool in such systems is not expected to contain significant amounts of highly labile (consumed within a period of hours to days) or even semilabile (consumed within a period of months to years; see Carlson 2002) compounds. In contrast, most continental aquatic environments are directly connected to a terrestrial source that delivers DOC within a time frame of hours or days (Müller et al., 2013), and terrestrial DOC is therefore freshly imported, but may still be either young or old (Mayorga et al., 2005; Raymond et al., 2007; 

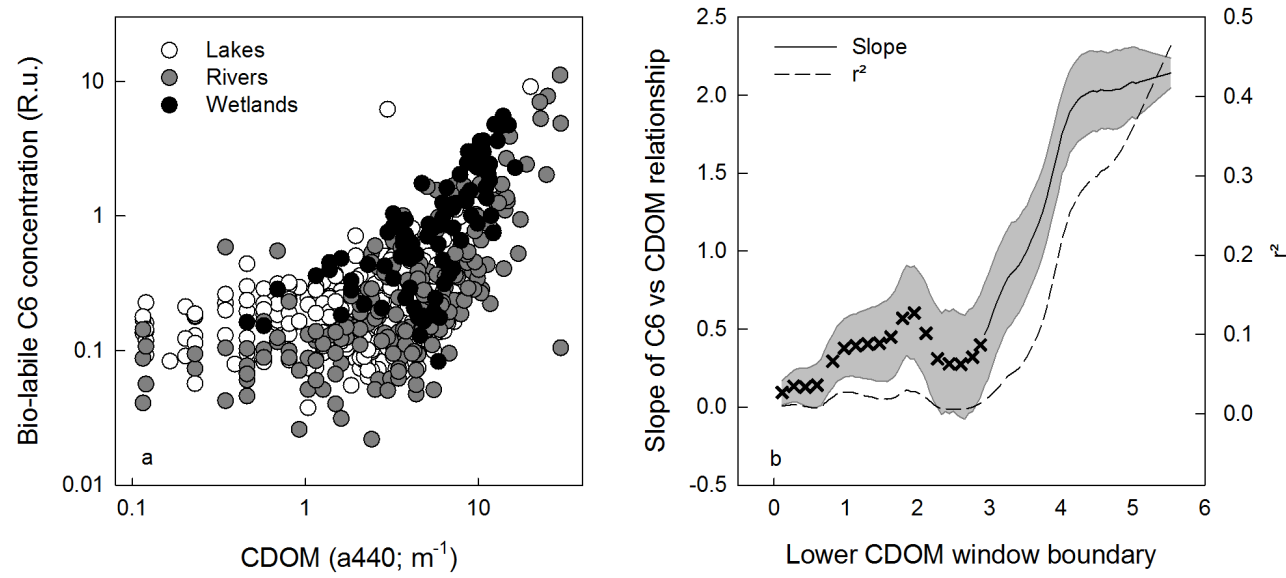

Figure 7. Concentrations of protein-like $\mathrm{C} 6$ as a function of CDOM in lakes, rivers and wetlands. (a) $r^{2}=0.32, p<0.001, n=519$. (b) Parameters of moving window regressions performed on discrete portions of the data set based on increasing CDOM. Total sample size was 519, but individual regressions were performed on subsets of 250 samples; a total of 270 regressions were thus performed. " $x$ " signs denote nonsignificant regressions. $x$ axis shows the lowest CDOM concentration included in the regression for which the parameters are reported. The first regression was thus performed on samples for which CDOM ranged from 0.12 to $3.11 \mathrm{~m}^{-1}$, whereas the last regression was performed on samples for which CDOM ranged from 5.55 to $30.0 \mathrm{~m}^{-1}$. Note that the slope characterizes the $\log (\mathrm{C} 6) \mathrm{vs} . \log (\mathrm{CDOM})$ relationship.

Marín-Spiotta et al., 2014). Recent work suggests that freshly imported terrestrial organic carbon can be readily degraded in lakes and rivers even if it is extremely old (McCallister and del Giorgio, 2012; Kleber et al., 2011), thus suggesting that age and origin may not be the best predictors of DOC biological degradability across continental and marine waters.

Freshness thus appears to be a better common driver than age or origin to place apparently differing patterns of DOC biological degradability on a common gradient that is independent of the type of aquatic ecosystem studied. In this regard, studies in arctic rivers have shown that DOC is typically more labile during the spring freshet (Mann et al., 2012; Holmes et al., 2008), when DOC has been freshly imported into the aquatic environment. Likewise, DOC was more labile in temperate streams characterized by low temperatures, presumably because it has been less altered than the DOC found in warmer streams and thus conserved in a "fresher" state (Lu et al., 2013). Our results suggest that the same basic pattern may apply not only seasonally, but also across the whole boreal aquatic network: close to the land-water interface, most of the biologically labile DOC appears to be of terrestrial origin, as suggested by the increasingly tight coupling between CDOM (measured as absorbance at $440 \mathrm{~nm}$; see Methods) and biolabile component C6 as CDOM increases (Fig. 7). Furthermore, the highest concentrations and proportions of both biologically and photochemically labile DOC are found in low-order rivers and wetlands (Fig. 2), supporting the notion that these are major hotspots for biogeochemical processes in continental waters (Denfeld et al., 2013; Campeau et al., 2014). Systems with greater CDOM content thus tend to contain higher concentrations of bio- logically and photochemically degradable DOC (Lapierre et al., 2013), because in such environments the DOM pool is fresher and contains high amounts of photosensitive DOM (Fig. 6, Table 1), as well as biolabile, protein-like DOM (Fig. 7, Table 1) which interestingly closely resembles DOM from autochthonous origin (Stedmon et al., 2007; Lapierre and Frenette, 2009; Fig. 7).

\subsection{The underlying basis of patterns in degradable DOC}

The patterns in the concentrations of biologically and photochemically degradable DOC reported here allow identifying DOM pools and environmental factors that are linked to DOC degradability across boreal freshwater networks. In our study the amounts of BDOC and PDOC were measured separately, but there are known synergistic effects between the biological and photochemical processing of DOC in natural environments (Miller and Moran, 1997), wherein biological and photochemical processes may operate on the same DOM pool (Koehler et al., 2012). The overall degradation potential of DOC could thus be different in ambient waters where these processes actually co-occur, as opposed to our experimental conditions where no such interaction was possible. The objective of this study, however, was not to estimate the total concentration of degradable DOC, or the realized expression of this potential degradability in situ, but rather to explore the large-scale patterns in BDOC and PDOC and their respective drivers across a wide variety of aquatic environments in the most comparable manner possible.

Both intrinsic DOM properties and environmental conditions appeared to play a role in determining the 
concentrations and relative proportions of degradable DOC observed in these boreal freshwater environments. BDOC was linked to nutrient concentration, and to DOM concentration and composition (Fig. 5, Table 1). The influence of TN (and TP) on BDOC may be threefold: (1) it may be related to increased primary production and thus to the production of an autochthonous BDOC component (Descy et al., 2002; Demarty and Prairie, 2009), (2) it may be related to the stimulating effect of nutrients on DOC degradation rates (Wickland et al., 2012; Guillemette et al., 2013), and (3) it may be related to DOM stoichiometry (Sun et al., 1997; Fellman et al., 2009). Chlorophyll $a$ concentration, however, was unrelated to BDOC, and although we did not determine organic $\mathrm{N}$, our measurements show that the sum of ammonium, nitrates and nitrites represented on average $8 \%$ of $\mathrm{TN}$, and never more than $50 \%$. These results thus suggest that an important fraction of the $\mathrm{N}$ in our systems was in the form of DON and contained within the DOM itself along with DOC. The same is probably true for $\mathrm{P}$, although we do not have measurements of inorganic $\mathrm{P}$ to support this contention. It would seem that the inclusion of $\mathrm{N}$ as a predictor of BDOC is mostly (although not exclusively) reflecting intrinsic DOM properties, i.e., the stoichiometry and therefore quality of the DOM that was originally loaded from land. This potential effect of DOM quality was reflected in absorbance and fluorescence analyses, as protein-like C6 was the only DOM optical property that was related to BDOC, consistent with previous studies (Guillemette and del Giorgio, 2011; Fellman et al., 2008). The contribution percentage of C6 to total fluorescence was further strongly and positively related to the a250:a365 ratio, and negatively to SUVA 254 (Fig. 5), consistent with previously reported relationships of those absorbance properties with microbial processes such as bacterial production and growth efficiency (Berggren et al., 2008).

The patterns in PDOC, however, were exclusively explained by DOM optical properties (Table 1). Extrinsic chemical factors are known to drive the photochemical degradation of DOC (Porcal et al., 2014), and PDOC was indeed significantly correlated with $\mathrm{pH}\left(r^{2}=0.13, p<0.001\right.$, $n=391)$ and iron concentration $\left(r^{2}=0.35, p<0.001, n=\right.$ 216). These variables, however, were not significant when included in multiple linear regression models containing DOM concentration or composition, and CDOM entirely accounted for the concentration effect of FDOM (Table 1), suggesting that water color integrates several key biochemical properties that collectively determine photochemical reactivity. The connection of PDOC with CDOM or terrestrial influence in general is intuitive, as land-derived DOM is typically associated with highly photoreactive material with high humic and lignin contents (Spencer et al., 2009b; Hernes et al., 2009; Stubbins et al., 2010). The average loss of DOC in our incubations was $13 \%$, whereas on average $41 \%$ of CDOM was lost during the same experiments. This supports the widely accepted notion that colored DOM is preferentially removed by photochemical oxidation (Graneli et al.,
1996; Weyhenmeyer et al., 2012) and more importantly suggests that specific DOM pools (as shown by fluorescence components) contribute more than others to the photochemical losses of DOC (Lu et al., 2013): the degradability of the various fluorescence components (Fig. 6) mostly reflects the degree to which they absorb light in the UV-A region (Fig. 4). These results thus suggest a strong top-down control of DOM composition by photochemical processes, which is reflected in the large-scale patterns of DOM composition across boreal freshwater ecosystems. Certain fluorescence components were extremely photosensitive (Fig. 6); in particular, component $\mathrm{C} 3$ was typically completely degraded by light within $24 \mathrm{~h}$ (Fig. 6). The ambient waters differ from experimental conditions in terms of the light climate, but these results nonetheless suggest that there are substantial losses of these fluorescence components in natural environments, and clearly indicate that the photochemical loss rates of $\mathrm{C} 3$ are much faster than those of other components. This implies that there must be a constant replenishment of this very reactive DOM across continental watersheds in order to maintain the observed concentrations, such that the contribution of this highly photosensitive DOM (e.g., C3) to aquatic biogeochemical processes is probably greater than what is suggested by its ambient concentrations alone.

\subsection{Linking DOM optical properties to degradability patterns}

Previous work has shown that the links between the patterns of DOC consumption and the dynamics of specific DOM pools identified on the basis of fluorescence are much more complex than what is generally recognized, because most of these components appear to be both consumed and produced by biotic and abiotic processes across diverse aquatic environments (Guillemette and del Giorgio, 2012; RomeraCastillo et al., 2011; Kothawala et al., 2013b). In this regard, Fig. 6 shows a consistent behavior of the various fluorescence components in response to irradiation across lakes, rivers and wetlands with very different environmental properties. It also shows that concentrations of humic/fulvic component C4 systematically increased after exposure to sunlight, yet this component covaries positively and significantly with PDOC $\left(r^{2}=0.30, p<0.001\right)$. Photosensitive component C3 (Fig. 5) also covaries positively with PDOC (Table 1 ), but clearly the mechanism underlying both relationships is completely different.

Component $\mathrm{C} 4$ has an emission spectrum comparable to that of very photoreactive $\mathrm{C} 3$, but the excitation spectrum shifts towards shorter wavelengths (Fig. 4), suggesting that the former may be a photoproduct of the latter. Given its excitation spectrum (Fig. 4), however, it is unlikely that component $\mathrm{C} 4$ is unreactive to irradiation; Fig. 6 most likely reflects the net balance of co-occurring photochemical production and degradation processes rather than true reactivity, suggesting that DOC that is potentially photoreactive 
may be produced autochthonously in aquatic ecosystems via photochemical processes. Likewise, it has been shown that photoreactive components such as component $\mathrm{C} 3$ reported here are also systematically produced by microbial processes during controlled incubations (Guillemette and del Giorgio, 2012). To add complexity to this framework, not only may biologically labile DOC be produced from the photochemical alteration of terrestrially derived DOC (Bertilsson et al., 1999; Cory et al., 2013), but it can also be rendered more recalcitrant to microbial degradation upon exposure to solar radiation (Tranvik and Bertilsson, 2001). It is difficult to quantify those interactions, in particular the biotic (Guillemette and del Giorgio, 2012) and abiotic (Fig. 6) production of PDOC, but those different results nonetheless highlight the multiple processes, on land and in the water, which fuel the aquatic pools of both BDOC and PDOC. Linking DOC degradability measurements with DOM optical properties allows us to uncover some of those interactions between production and removal processes, which may not be detected purely based on the characterization of the DOM found in ambient waters.

In the present study we have identified specific fluorescent DOM components associated with either the biological or photochemical degradability of the ambient DOC pool across hundreds of lakes, rivers and wetlands (Table 1, Figs. 3, 5). Our own work in this regard (Stubbins et al., 2014) suggests that these fluorescent components involve not only the molecules responsible for the fluorescence properties, but also that they tend to covary with a host of other, nonfluorescent compounds. The molecules responsible for the actual fluorescence of these components may be acting both as substrates and perhaps more importantly as tracers of a variety of nonfluorescent pools that share similar sources and sinks, and which may themselves be the main substrates of these microbial reactions.

In this regard, the very strong photochemical degradability of component $\mathrm{C} 3$ (Fig. 5), combined with published evidence of consistent losses of a comparable component over a gradient of land cover and water retention time in the landscape (Kothawala et al., 2013b; Lu et al., 2013), suggests that it is indeed acting as a substrate for photochemical degradation, and that $\mathrm{C} 3$ is a causal driver of PDOC in freshwater environments. Our measurements, however, cannot confirm whether component $\mathrm{C} 6$ is mostly driving BDOC as a substrate for microbial processes or acting as a tracer of covarying biolabile molecules. Regardless, our results indicate that BDOC and PDOC pools may be adequately tracked by specific DOM properties across a large diversity of freshwater environments, presumably because optical measurements allow targeting meaningful DOM pools comprising different molecules which share common production, importation, and removal processes.

\subsection{Land as a source of both biologically and photochemically degradable DOC}

Although it may appear intuitive that both BDOC and PDOC increase with overall DOC, the coupling between the concentrations of BDOC and PDOC implies that they share at least some basic sinks or, more likely, sources, in boreal watersheds. The biological and photochemical processes responsible for the removal of DOC from those boreal freshwaters are driven by different extrinsic variables and target different DOM pools (Table 1, Fig. 6), and the biological and photochemical degradability of DOC, expressed as the fraction of DOC that is biologically or photochemically degradable in standardized conditions, are completely decoupled (Fig. 3a). The collective evidence discussed above thus rather suggests that BDOC and PDOC partly share land as a common origin, and the relatively weak coupling between both DOC pools suggests that the relative contribution of land-derived DOC to BDOC differs greatly across systems.

In this regard, autochthonous processes such as phytoplankton and macrophyte primary production are known to generate fresh, protein-like DOM in freshwaters (Demarty and Prairie, 2009; Lapierre and Frenette, 2009) and more importantly may supply the BDOC pool independently of terrestrial sources. This appears to be the case in several systems studied here, as the coupling between PDOC and BDOC was weaker in lakes (Fig. 3b), and the amount of biolabile DOM, expressed in the patterns of component C6, was completely independent of CDOM in the lower portion of the CDOM gradient (Fig. 7) where most lakes and some large rivers were found. A comparable pattern has been reported in Swedish lakes (Kothawala et al., 2013b) where the equivalent proteinlike FDOM component appeared to be relatively invariable across gradients of lake DOC and water retention time. Contrary to that study, however, we observed a stronger relationship between C6 and CDOM as CDOM increased (Fig. 7), such that highly colored systems (mostly streams and wetlands) contained much higher concentrations of component C6. The inclusion of rivers ranging from Strahler order 1 to 6 , and of a diversity of wetlands, greatly expands the range of terrestrial influence relative to what can be observed based on lakes alone, and may explain the differences between our two studies. This may be a combination of low macrophyte cover and algal biomass in these typically oligotrophic boreal systems, the inhibition of autochthonous processes by CDOM-induced light limitation (Karlsson et al., 2009) and, perhaps more importantly, the high rate of supply of terrestrial labile DOC in highly colored systems (Berggren et al., 2010a).

There would thus appear to be a baseline of autochthonous BDOC that is always present in those aquatic environments and varies more or less randomly across gradients of CDOM in response to simultaneously increasing nutrients (Lapierre and del Giorgio, 2012) and light limitation (Karlsson et al., 2009). This baseline may be reflected in the significant 
intercept of the relationship between BDOC and PDOC (Fig. 3b), which would suggest that in systems with very low terrestrial influence and almost no PDOC, there is still a significant pool of BDOC that is likely from autochthonous origin. Autochthonous sources may indeed be the main driver of BDOC across narrow CDOM gradients, as previously reported (Kritzberg et al., 2004; Guillemette et al., 2013; McCallister and del Giorgio, 2008), but the land-derived BDOC might be the one pool which varies consistently across gradients of terrestrial influence and may thus better explain the patterns in DOC degradability across continental watersheds. These patterns collectively suggest that terrestrially derived BDOC increases proportionately faster than or independently of autochthonous BDOC along a gradient of increasing CDOM, such that land becomes an important and even main source of BDOC as terrestrial influence increases. This in turn may explain why biolabile component C6 (and the molecules it tracks) may actually accumulate and reach high concentrations in wetlands and rivers with very high terrestrial influence, whereas in lakes it is typically decoupled from CDOM (Fig. 7), as well as from DOC concentrations and water retention time (Kothawala et al., 2013b), since in the latter systems production, importation and removal may be closer to steady state.
Our results highlight the apparent links that tie terrestrial influence, water retention time and DOC freshness with DOC composition and degradability across boreal freshwaters. In a previous study we had shown that the concentrations of both BDOC and PDOC tended to increase with CDOM content (Lapierre et al., 2013), resulting in increases in $\mathrm{CO}_{2}$ flux. This result also suggested an additive dynamic of DOC degradability along a gradient of terrestrial influence, and here we show that the role of land as a major source of both biologically and photochemically degradable DOC to continental watersheds results in a pattern of covariation between these two key pools of carbon across boreal aquatic networks, despite fundamental contrasts in terms of their composition and regulation. The potential of terrestrially derived organic carbon to contribute to ecological and biogeochemical processes in boreal freshwaters is thus apparently not limited by its degradability, at least in environments with high terrestrial influence where this carbon has been freshly imported. 


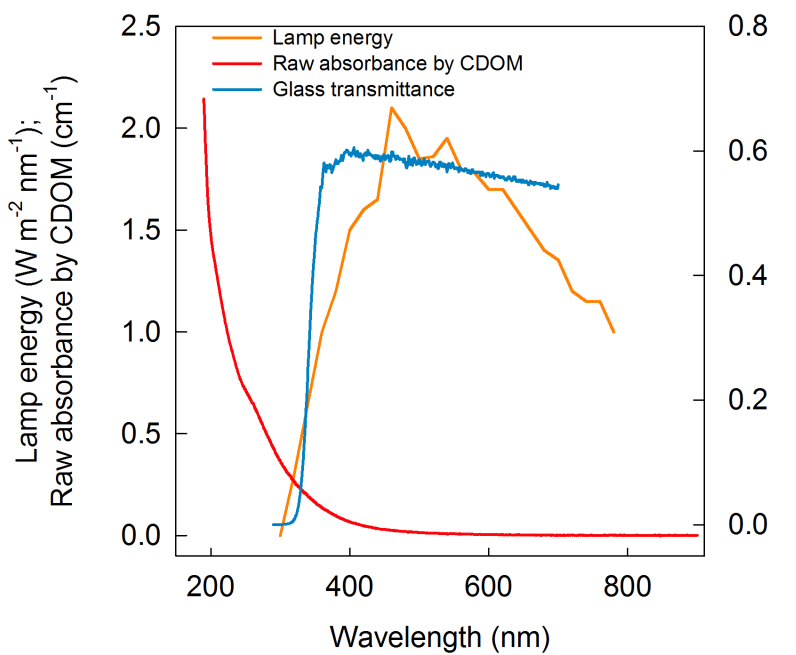

Figure A1. Comparing the lamp spectrum to light absorption from the glass and from CDOM. The same scan was used to correct for absorption of light by glass for all the samples, whereas the corresponding CDOM scan was used for each sample; the illustrated CDOM scan corresponds to a representative river sample.

\section{Appendix A: Standardizing PDOC based on average light dose in the experimental tubes}

One of the main objectives of this study was to assess the patterns in the concentrations of photochemically degradable DOC, in the most standardized way possible. While the photochemical degradation experiments have been conducted in standardized conditions in terms of incoming light dose, exposure time and temperature, the average light dose within the experimental tubes varied depending on CDOM content which attenuated a fraction of the incoming light and resulted in self-shading. We tested the potential significance of this self-shading effect on the reported patterns by comparing the uncorrected PDOC values to light-standardized concentrations, which were obtained by dividing each PDOC concentration by the average light energy available (accounting for self-shading; see below) in the corresponding tube in which the experiment was conducted. Absorbance scans were obtained for half of an empty glass tube (to account for the energy lost when passing through the glass; see Fig. A1) as well as for the CDOM contained in each sample, as described in the Methods section. The tubes were round, horizontally disposed in the solar simulator and had an inner diameter of $24 \mathrm{~mm}$, so we calculated the proportion of each wavelength that was remaining in 10 different $2.4 \mathrm{~mm}$ thick sections of the tube. The solar simulator light had a total light dose of $750 \mathrm{~W} \mathrm{~m}^{-2}$ and a spectrum representative of the sunlight (Fig. A1), which was used to calculate the total amount of light energy (in $\mathrm{W} \mathrm{m}^{-2}$ ) available in each section of the experimental tube by multiplying the incoming light dose by (1-fraction absorbed (by glass and CDOM)). Only the 300$450 \mathrm{~nm}$ range of wavelengths was used. The lamp emitted a
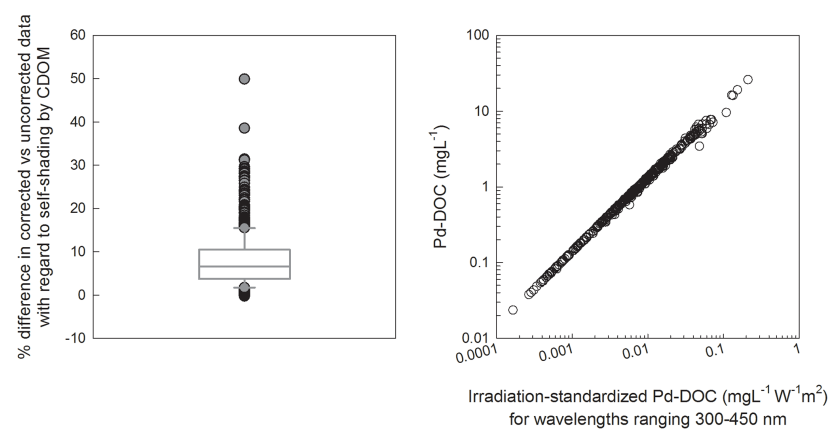

Figure A2. Comparing uncorrected vs. light-standardized concentrations of PDOC based on CDOM self-shading for wavelengths ranging $300-450 \mathrm{~nm}$.

wide range of longer wavelengths, which were not significantly absorbed by either the glass or CDOM; thus, although those wavelengths $(450-750 \mathrm{~nm})$ contribute a large fraction of the total energy delivered, they typically do not contribute much to photochemical processes (Vähätalo et al., 2000). Including these wavelengths would thus tend to attenuate the cross-sample differences in average light dose.

We then calculated a weighted average in the amount of light energy contained in the 10 layers based on the relative volume that each occupies in the tube. The average light dose varied little in the tubes (see Sect. 2.4 in Methods) but the measured concentrations in PDOC among samples varied by more than 3 orders of magnitude (Fig. $3 b$ ). As a result, although standardizing the raw PDOC values by the average effective light dose within the corresponding experimental tube resulted in a certain bias when comparing the lowest to the highest CDOM samples, when these individual differences are put in perspective of the whole set of PDOC data (which ranges over several orders of magnitude) the little amount of variation that is generated the relationship is barely noticeable (Fig. A2). There was a small amount of variation for the highest CDOM samples, but this potential variation is arguably smaller than the measurement error in other reported variables against which PDOC is correlated. We thus chose to present uncorrected $\mathrm{PDOC}$ values, which are more intuitively comparable to the concentrations of BDOC (in $\mathrm{mg} \mathrm{L}^{-1}$ ) that we report in this study. 
Acknowledgements. This work is part of the Carbon Biogeochemistry in Boreal Aquatic Systems (CarBBAS) research chair, co-funded by the Natural Science and Engineering Research Council of Canada (NSERC) and Hydro-Québec. We thank A. St-Pierre, A. Parkes and the CarBBAS team for the contribution to the field and laboratory components of this study, and we thank P. Massicotte, T. Rasilo, C. Ruiz-Gonzalez, D. Vachon and F. Guillemette for constructive discussions and comments on early versions of the manuscript.

Edited by: T. J. Battin

\section{References}

Algesten, G., Sobek, S., Bergstrom, A. K., Agren, A., Tranvik, L. J., and Jansson, M.: Role of lakes for organic carbon cycling in the boreal zone, Glob. Change Biol., 10, 141-147, 2004.

Amon, R. M. W. and Benner, R.: Bacterial utilization of different size classes of dissolved organic matter, Limnol. Oceanogr., 41, 41-51, 1996.

Anderson, T. R. and Williams, P. J. 1. B.: A one-dimensional model of dissolved organic carbon cycling in the water column incorporating combined biological-photochemical decomposition, Glob. Biogeochem. Cycle, 13, 337-349, doi:10.1029/1999gb900013, 1999.

APHA, A.: Standard methods for the examination of water and wastewater, 20, 1998.

Battin, T. J., Kaplan, L. A., Findlay, S., Hopkinson, C. S., Marti, E., Packman, A. I., Newbold, J. D., and Sabater, F.: Biophysical controls on organic carbon fluxes in fluvial networks, Nat. Geosci., 1, 95-100, doi:10.1038/ngeo101, 2008.

Benner, R., and Kaiser, K.: Biological and photochemical transformations of amino acids and lignin phenols in riverine dissolved organic matter, Biogeochemistry, 102, 209-222, doi:10.1007/s10533-010-9435-4, 2011.

Berggren, M., Laudon, H., and Jansson, M.:Hydrological control of organic carbon support for bacterial growth in boreal headwater streams, Microb. Ecol., 57, 170-178, 2009.

Berggren, M., Laudon, H., Haei, M., Strom, L., and Jansson, M.: Efficient aquatic bacterial metabolism of dissolved low-molecularweight compounds from terrestrial sources, Isme J., 4, 408-416, doi:10.1038/ismej.2009.120, 2010a.

Berggren, M., Strom, L., Laudon, H., Karlsson, J., Jonsson, A., Giesler, R., Bergstrom, A. K., and Jansson, M.: Lake secondary production fueled by rapid transfer of low molecular weight organic carbon from terrestrial sources to aquatic consumers, Ecol. Lett., 13, 870-880, doi:10.1111/j.14610248.2010.01483.x, 2010b.

Berggren, M., Lapierre, J.-F., and del Giorgio, P. A.: Magnitude and regulation of bacterioplankton respiratory quotient across freshwater environmental gradients, ISME J, 6, 984-993, doi:10.1038/ismej.2011.157, 2012.

Bertilsson, S. and Tranvik, L. J.: Photochemically produced carboxylic acids as substrates for freshwater bacterioplankton, Limnol. Oceanogr., 43, 885-895, 1998.

Bertilsson, S., Stepanauskas, R., Cuadros-Hansson, R., Graneli, W., Wikner, J., and Tranvik, L.: Photochemically induced changes in bioavailable carbon and nitrogen pools in a boreal watershed, Aquat. Microb. Ecol., 19, 47-56, 1999.

Brett, M. T., Kainz, M. J., Taipale, S. J., and Seshan, H.: Phytoplankton, not allochthonous carbon, sustains herbivorous zooplankton production, P. Natl. Acad. Sci., 106, 21197-21201, doi:10.1073/pnas.0904129106, 2009.

Butman, D. and Raymond, P. A.: Significant efflux of carbon dioxide from streams anr rivers in the United States, Nat. Geosci., 4, 839-842, doi:10.1038/NGE01294, 2011.

Campeau, A., Lapierre, J.-F., Vachon, D., and del Giorgio, P. A.: Regional contribution of $\mathrm{CO}_{2}$ and $\mathrm{CH}_{4}$ fluxes from the fluvial network in a lowland boreal landscape of Québec, Glob. Biogeochem. Cycle, 28, 57-69, doi:10.1002/2013gb004685, 2014.

Carlson, C. A.: Production and removal processes, in: Biogeochemistry of marine dissolved organic matter, edited by: Hansell, D A., and Carlson, C. A., Elsevier, 2002.

Cole, J. J., Prairie, Y. T., Caraco, N. F., McDowell, W. H., Tranvik, L. J., Striegl, R. G., Duarte, C. M., Kortelainen, P., Downing, J. A., Middelburg, J. J., and Melack, J.: Plumbing the global carbon cycle: Integrating inland waters into the terrestrial carbon budget, Ecosystems, 10, 171-184, doi:10.1007/s10021-006-9013-8, 2007.

Cory, R. M. and McKnight, D. M.: Fluorescence spectroscopy reveals ubiquitous presence of oxidized and reduced quinones in dissolved organic matter, Environ. Sci. Technol., 39, 8142-8149, doi:10.1021/es0506962, 2005.

Cory, R. M., Crump, B. C., Dobkowski, J. A., and Kling, G. W.: Surface exposure to sunlight stimulates $\mathrm{CO}_{2}$ release from permafrost soil carbon in the Arctic, P. Natl. Acad. Sci., 110, 34293434, doi:10.1073/pnas.1214104110, 2013.

Cuthbert, I. D. and del Giorgio, P.: Toward a strandard method of measuring color in fresh-water, Limnol. Oceanogr., 37, 13191326, 1992.

del Giorgio, P. A., Cole, J. J., Caraco, N. F., and Peters, R. H.: Linking planktonic biomass and metabolism to net gas fluxes in northern temperate lakes, Ecology, 80, 1422-1431, 1999.

Demarty, M. and Prairie, Y. T.: In situ dissolved organic carbon (DOC) release by submerged macrophyte-epiphyte communities in southern Quebec lakes, Can. J. Fish. Aquat. Sci., 66, 1522 1531, doi:10.1139/f09-099, 2009.

Denfeld, B. A., Frey, K. E., Sobczak, W. V., Mann, P. J., and Holmes, R. M.: Summer CO 2 evasion from streams and rivers in the Kolyma River basin, north-east Siberia, Polar Research, 2013.

Descy, J.-P., Leporcq, B., Viroux, L., François, C., and Servais, P.: Phytoplankton production, exudation and bacterial reassimilation in the River Meuse (Belgium), J. Plankton Res., 24, 161166, doi:10.1093/plankt/24.3.161, 2002.

Dittmar, T. and Kattner, G.: The biogeochemistry of the river and shelf ecosystem of the Arctic Ocean: a review, Mar. Chem., 83, 103-120, doi:10.1016/S0304-4203(03)00105-1, 2003.

Fasching, C., Behounek, B., Singer, G. A., and Battin, T. J.: Microbial degradation of terrigenous dissolved organic matter and potential consequences for carbon cycling in brown-water streams, Scientific reports, 4, doi:10.1038/srep04981, 2014.

Fellman, J. B., D’Amore, D. V., Hood, E., and Boone, R. D.: Fluorescence characteristics and biodegradability of dissolved organic matter in forest and wetland soils from coastal temperate 
watersheds in southeast Alaska, Biogeochemistry, 88, 169-184, doi:10.1007/s10533-008-9203-x, 2008.

Fellman, J. B., Hood, E., D'Amore, D. V., Edwards, R. T., and White, D.: Seasonal changes in the chemical quality and biodegradability of dissolved organic matter exported from soils to streams in coastal temperate rainforest watersheds, Biogeochemistry, 95, 277-293, doi:10.1007/s10533-009-9336-6, 2009.

Findlay, S., and Sinsabaugh, R. L.: Aquatic ecosystems: Interactivity of dissolved organic matter Aquatic Ecology, Academic press, San Diego, 2002.

Graneli, W., Lindell, M., and Tranvik, L.: Photo-oxidative production of dissolved inorganic carbon in lakes of different humic content, Limnol. Oceanogr., 41, 698-706, 1996.

Guillemette, F. and del Giorgio, P. A.: Reconstructing the various facets of dissolved organic carbon bioavailability in freshwater ecosystems, Limnol. Oceanogr., 56, 734-748, doi:10.4319/lo, 2011.

Guillemette, F. and del Giorgio, P. A.: Simultaneous consumption and production of fluorescent dissolved organic matter by lake bacterioplankton, Environmental Microbiology, 14, 1432-1443, doi:10.1111/j.1462-2920.2012.02728.x, 2012.

Guillemette, F., McCallister, S. L., and del Giorgio, P. A.: Differentiating the degradation dynamics of algal and terrestrial carbon within complex natural dissolved organic carbon in temperate lakes, J. Geophys. Res.-Biogeo., 118, 963-973, doi:10.1002/jgrg.20077, 2013.

Hedges, J. I., Clark, W. A., and Cowie, G. L.: Fluxes and reactivities of organic-matter in a coastal marine bay, Limnol. Oceanogr., 33, 1137-1152, 1988.

Hernes, P. J., Bergamaschi, B. A., Eckard, R. S., and Spencer, R. G. M.: Fluorescence-based proxies for lignin in freshwater dissolved organic matter, J. Geophys. Res.-Biogeo., 114, doi:10.1029/2009jg000938, 2009.

Holmes, R. M., Aminot, A., Kérouel, R., Hooker, B. A., and Peterson, B. J.: A simple and precise method for measuring ammonium in marine and freshwater ecosystems, Can. J. Fish. Aquat. Sci., 56, 1801-1808, doi:10.1139/f99-128, 1999.

Holmes, R. M., McClelland, J. W., Raymond, P. A., Frazer, B. B., Peterson, B. J., and Stieglitz, M.: Lability of DOC transported by Alaskan rivers to the arctic ocean, Geophys. Res. Lett., 35, 5, L03402, doi:10.1029/2007g1032837, 2008.

Jansson, M., Persson, L., De Roos, A. M., Jones, R. I., and Tranvik, L. J.: Terrestrial carbon and intraspecific size-variation shape lake ecosystems, Trends Ecol. Evol., 22, 316-322, doi:10.1016/j.tree.2007.02.015, 2007.

Jonsson, A., Meili, M., Bergstrom, A. K., and Jansson, M.: Wholelake mineralization of allochthonous and autochthonous organic carbon in a large humic lake (Ortrasket, N. Sweden), Limnol. Oceanogr., 46, 1691-1700, 2001.

Karlsson, J., Jonsson, A., Meili, M., and Jansson, M.: Control of zooplankton dependence on allochthonous organic carbon in humic and clear-water lakes in northern Sweden, Limnol. Oceanogr., 48, 269-276, 2003.

Karlsson, J., Bystrom, P., Ask, J., Ask, P., Persson, L., and Jansson, M.: Light limitation of nutrient-poor lake ecosystems, Nature, 460, 506-509, doi:10.1038/nature08179, 2009.

Kleber, M., Nico, P. S., Plante, A., Filley, T., Kramer, M., Swanston, C., and Sollins, P.: Old and stable soil organic matter is not necessarily chemically recalcitrant: implications for modeling con- cepts and temperature sensitivity, Glob. Change Biol., 17, 10971107, 2011.

Koehler, B., Wachenfeldt, E., Kothawala, D., and Tranvik, L. J.: Reactivity continuum of dissolved organic carbon decomposition in lake water, J. Geophys. Res.-Biogeo., 117, doi:10.1029/2011JG001793, 2012.

Kothawala, D. N., Murphy, K. R., Stedmon, C. A., Weyhenmeyer, G. A., and Tranvik, L. J.: Inner filter correction of dissolved organic matter fluorescence, Limnol. Oceanogr.: Methods, 11, 616-630, 2013a.

Kothawala, D. N., Stedmon, C. A., Müller, R. A., Weyhenmeyer, G. A., Köhler, S. J., and Tranvik, L. J.: Controls of dissolved organic matter quality: Evidence from a large-scale boreal lake survey, Glob. Change Biol., 20, 1101-1114, doi:10.1111/gcb.12488, 2013b.

Kritzberg, E. S., Cole, J. J., Pace, M. L., Graneli, W., and Bade, D. L.: Autochthonous versus allochthonous carbon sources of bacteria: Results from whole-lake C-13 addition experiments, Limnol. Oceanogr., 49, 588-596, 2004.

Lapierre, J. F., and Frenette, J. J.: Effects of macrophytes and terrestrial inputs on fluorescent dissolved organic matter in a large river system, Aquat. Sci., 71, 15-24, doi:10.1007/s00027-009-9133-2, 2009.

Lapierre, J. F., and del Giorgio, P. A.: Geographic and environmental drivers of regional differences in the lake $p \mathrm{CO}_{2}$ versus DOC relationship across northern landscapes, J. Geophys. Res.Biogeo., 117, doi:10.1029/2012JG001945, 2012.

Lapierre, J. F., Guillemette, F., Berggren, M., and del Giorgio, P.: Increases in terrestrially derived carbon stimulate organic carbon processing and $\mathrm{CO}_{2}$ emissions in boreal aquatic ecosystems, Nature communications, 4, 2972, doi:10.1038/ncomms3972, 2013.

Lu, Y., Bauer, J. E., Canuel, E. A., Yamashita, Y., Chambers, R. M., and Jaffé, R.: Photochemical and microbial alteration of dissolved organic matter in temperate headwater streams associated with different land use, J. Geophys. Res.-Biogeo., 118, 566-580, doi:10.1002/jgrg.20048, 2013.

Mann, P. J., Davydova, A., Zimov, N., Spencer, R. G. M., Davydov, S., Bulygina, E., Zimov, S., and Holmes, R. M.: Controls on the composition and lability of dissolved organic matter in Siberia's Kolyma River basin, J. Geophys. Res.-Biogeo., 117, 15, G01028, doi:10.1029/2011jg001798, 2012.

Marín-Spiotta, E., Gruley, K. E., Crawford, J., Atkinson, E. E., Miesel, J. R., Greene, S., Cardona-Correa, C., and Spencer, R. G. M.: Paradigm shifts in soil organic matter research affect interpretations of aquatic carbon cycling: transcending disciplinary and ecosystem boundaries, Biogeochemistry, 117, 279297, doi:10.1007/s10533-013-9949-7, 2014.

Marker, A. and Nusch, E.: The measurement of photosynthetic pigments in freshwaters and standardization of methods: conclusion and recommendation, edited by: Rai, H. and Riemann, B., Arch. Hydrobiol. Beih. Ergebn. Limnol, 14, 91-106, 1980.

Massicotte, P. and Frenette, J.-J.: Spatial connectivity in a large river system: resolving the sources and fate of dissolved organic matter, Ecol. Appl., 21, 2600-2617, 2011.

Mayorga, E., Aufdenkampe, A. K., Masiello, C. A., Krusche, A. V., Hedges, J. I., Quay, P. D., Richey, J. E., and Brown, T. A.: Young organic matter as a source of carbon dioxide outgassing from Amazonian rivers, Nature, 436, 538-541, doi:10.1038/nature03880, 2005. 
McCallister, S. L. and del Giorgio, P. A.: Direct measurement of the delta C-13 signature of carbon respired by bacteria in lakes: Linkages to potential carbon sources, ecosystem baseline metabolism, and $\mathrm{CO}_{2}$ fluxes, Limnol. Oceanogr., 53, 1204-1216, 2008.

McCallister, S. L. and del Giorgio, P. A.: Evidence for the respiration of ancient terrestrial organic $\mathrm{C}$ in northern temperate lakes and streams, P. Natl. Acad. Sci., 109, 16963-16968, doi:10.1073/pnas.1207305109, 2012.

Miller, M. P., Simone, B. E., McKnight, D. M., Cory, R. M., Williams, M. W., and Boyer, E. W.: New light on a dark subject: comment, Aquat. Sci., 72, 269-275, doi:10.1007/s00027010-0130-2, 2010.

Miller, W. L. and Moran, M. A.: Interaction of photochemical and microbial processes in the degradation of refractory dissolved organic matter from a coastal marine environment, Limnol. Oceanogr., 42, 1317-1324, 1997.

Molot, L. A. and Dillon, P. J.: Photolytic regulation of dissolved organic carbon in northern lakes, Glob. Biogeochem. Cycle, 11, 357-365, 1997.

Müller, R. A., Futter, M. N., Sobek, S., Nisell, J., Bishop, K., and Weyhenmeyer, G. A.: Water renewal along the aquatic continuum offsets cumulative retention by lakes: implications for the character of organic carbon in boreal lakes, Aquat. Sci., 75, 535545, doi:10.1007/s00027-013-0298-3, 2013.

Murphy, K. R., Butler, K. D., Spencer, R. G. M., Stedmon, C. A., Boehme, J. R., and Aiken, G. R.: Measurement of Dissolved Organic Matter Fluorescence in Aquatic Environments: An Interlaboratory Comparison, Environ. Sci. Technol., 44, 9405-9412, doi:10.1021/es102362t, 2010.

Murphy, K. R., Stedmon, C. A., Wenig, P., and Bro, R.: OpenFluoran online spectral library of auto-fluorescence by organic compounds in the environment, Anal. Methods, 6, 658-661, 2014.

Obernosterer, I. and Benner, R.: Competition between biological and photochemical processes in the mineralization of dissolved organic carbon, Limnol. Oceanogr., 49, 117-124, 2004.

Porcal, P., Dillon, P. J., and Molot, L. A.: Interaction of extrinsic chemical factors affecting photodegradation of dissolved organic matter in aquatic ecosystems, Photochem. Photobiol. Sci., 13, 799-812, doi:10.1039/c4pp00011k, 2014.

Raymond, P. A., McClelland, J., Holmes, R., Zhulidov, A., Mull, K., Peterson, B., Striegl, R., Aiken, G., and Gurtovaya, T.: Flux and age of dissolved organic carbon exported to the Arctic Ocean: A carbon isotopic study of the five largest arctic rivers, Glob. Biogeochem. Cycle, 21, doi:10.1029/2007GB002934, 2007.

Romera-Castillo, C., Sarmento, H., Álvarez-Salgado, X. A., Gasol, J. M., and Marrasé, C.: Net production and consumption of fluorescent colored dissolved organic matter by natural bacterial assemblages growing on marine phytoplankton exudates, Appl. Environ. Microb., 77, 7490-7498, 2011.

Schmidt, M. W., Torn, M. S., Abiven, S., Dittmar, T., Guggenberger, G., Janssens, I. A., Kleber, M., Kögel-Knabner, I., Lehmann, J., and Manning, D. A.: Persistence of soil organic matter as an ecosystem property, Nature, 478, 49-56, 2011.

Shutova, Y., Baker, A., Bridgeman, J., and Henderson, R. K.: Spectroscopic characterisation of dissolved organic matter changes in drinking water treatment: From PARAFAC analysis to online monitoring wavelengths, Water Res., 54, 159-169, doi:10.1016/j.watres.2014.01.053, 2014.
Soumis, N., Lucotte, M., Larose, C., Veillette, F., and Canuel, R.: Photomineralization in a boreal hydroelectric reservoir: a comparison with natural aquatic ecosystems, Biogeochemistry, 86, 123-135, doi:10.1007/s10533-007-9141-z, 2007.

Spencer, R. G. M., Aiken, G. R., Butler, K. D., Dornblaser, M. M., Striegl, R. G., and Hernes, P. J.: Utilizing chromophoric dissolved organic matter measurements to derive export and reactivity of dissolved organic carbon exported to the Arctic Ocean: A case study of the Yukon River, Alaska, Geophys. Res. Lett., 36, doi:10.1029/2008g1036831, 2009a.

Spencer, R. G. M., Stubbins, A., Hernes, P. J., Baker, A., Mopper, K., Aufdenkampe, A. K., Dyda, R. Y., Mwamba, V. L., Mangangu, A. M., Wabakanghanzi, J. N., and Six, J.: Photochemical degradation of dissolved organic matter and dissolved lignin phenols from the Congo River, J. Geophys. Res.-Biogeo., 114, doi:10.1029/2009jg000968, 2009b.

Stedmon, C. A., Markager, S., and Bro, R.: Tracing dissolved organic matter in aquatic environments using a new approach to fluorescence spectroscopy, Mar. Chem., 82, 239-254, doi:10.1016/s0304-4203(03)00072-0, 2003.

Stedmon, C. A., Markager, S., Tranvik, L., Kronberg, L., Slatis, T., and Martinsen, W.: Photochemical production of ammonium and transformation of dissolved organic matter in the Baltic Sea, Mar. Chem., 104, 227-240, doi:10.1016/j.marchem.2006.11.005, 2007.

Stedmon, C. A., and Bro, R.: Characterizing dissolved organic matter fluorescence with parallel factor analysis: a tutorial, Limnol. Oceanogr. Meth., 6, 572-579, 2008.

Stubbins, A., Spencer, R. G., Chen, H., Hatcher, P. G., Mopper, K., Hernes, P. J., Mwamba, V. L., Mangangu, A. M., Wabakanghanzi, J. N., and Six, J.: Illuminated darkness: Molecular signatures of Congo River dissolved organic matter and its photochemical alteration as revealed by ultrahigh precision mass spectrometry, Limnol. Oceanogr., 55, 1467-1477, 2010.

Stubbins, A., Lapierre, J. F., Berggren, M., Prairie, Y. T., Dittmar, T., and del Giorgio, P. A.: What's in an EEM? Molecular Signatures Associated with Dissolved Organic Fluorescence in Boreal Canada, Environ. Sci. Technol., 48, 10598-10606, doi:10.1021/es502086e, 2014.

Sun, L., Perdue, E., Meyer, J., and Weis, J.: Use of elemental composition to predict bioavailability of dissolved organic matter in a Georgia river, Limnol. Oceanogr., 42, 714-721, 1997.

Tranvik, L. J. and Bertilsson, S.: Contrasting effects of solar UV radiation on dissolved organic sources for bacterial growth, Ecol. Lett., 4, 458-463, 2001.

Vähätalo, A. V., Salkinoja-Salonen, M., Taalas, P., and Salonen, K.: Spectrum of the quantum yield for photochemical mineralization of dissolved organic carbon in a humic lake, Limnol. Oceanogr., 45, 664-676, 2000.

Wallin, M. B., Grabs, T., Buffam, I., Laudon, H., Ågren, A., Öquist, M. G., and Bishop, K.: Evasion of $\mathrm{CO}_{2}$ from streams - The dominant component of the carbon export through the aquatic conduit in a boreal landscape, Glob. Change Biol., 19, 785-797, doi:10.1111/gcb.12083, 2013.

Ward, N. D., Keil, R. G., Medeiros, P. M., Brito, D. C., Cunha, A. C., Dittmar, T., Yager, P. L., Krusche, A. V., and Richey, J. E.: Degradation of terrestrially derived macromolecules in the Amazon River, Nat. Geosci., 6, 530-533, doi:10.1038/ngeo1817, 2013. 
Wenzel, A., Bergström, A.-K., Jansson, M., and Vrede, T.: Poor direct exploitation of terrestrial particulate organic material from peat layers by Daphnia galeata, Can. J. Fish. Aquat. Sci., 69, 1870-1880, doi:10.1139/f2012-110, 2012.

Weyhenmeyer, G. A., Fröberg, M., Karltun, E., Khalili, M., Kothawala, D., Temnerud, J., and Tranvik, L. J.: Selective decay of terrestrial organic carbon during transport from land to sea, Glob. Change Biol., 18, 349-355, doi:10.1111/j.13652486.2011.02544.x, 2012.
Wickland, K., Aiken, G., Butler, K., Dornblaser, M., Spencer, R., and Striegl, R.: Biodegradability of dissolved organic carbon in the Yukon River and its tributaries: Seasonality and importance of inorganic nitrogen, Glob. Biogeochem. Cycle, 26, doi:10.1029/2012GB004342, 2012.

Wickland, K. P., Neff, J. C., and Aiken, G. R.: Dissolved organic carbon in Alaskan boreal forest: Sources, chemical characteristics, and biodegradability, Ecosystems, 10, 1323-1340, doi:10.1007/s10021-007-9101-4, 2007. 